\title{
Management of glioblastoma: a perspective from Lithuania
}

\author{
Adomas Bunevicius ${ }^{1}$, Jurgita Usinskiene ${ }^{2,3}$, Inesa Buneviciene ${ }^{4}$, Ieva Vincerzevskiene ${ }^{2}$ \\ ${ }^{1}$ Lithuanian University of Health Sciences, Neuroscience Institute, Laboratory of Behavioral Medicine Kaunas, Kaunas, Lithuania; ${ }^{2}$ National Cancer \\ Institute, Vilnius, Lithuania; ${ }^{3}$ Faculty of Medicine, Vilnius University, Vilnius, Lithuania; ${ }^{4}$ Department of Communications, Vytautas Magnus \\ University, Kaunas, Lithuania \\ Correspondence to: Adomas Bunevicius, MD, PhD. Neuroscience Institute, Lithuanian University of Health Sciences, Eiveniu g 4, Kaunas, Lithuania. \\ Email: a.bunevicius@yahoo.com.
}

Submitted Nov 15, 2019. Accepted for publication Dec 22, 2019.

doi: 10.21037/cco.2019.11.04

View this article at: http://dx.doi.org/10.21037/cco.2019.11.04

\section{Socioeconomic status of Lithuania}

Lithuania is one the three Baltic states surrounded by Latvia, Belarus, Poland and Russia. Since 1940 Lithuania was occupied by the Soviet Union but declared its independence in 1991, and since 2004 is a member of the European Union (EU) (1). The population of Lithuania is 2,789,533, however this is a significant decline from 3,704,134 in 1991 (2). Lithuania belongs to a group of countries with a very high human development index (3). It is a high-income country with mean GDP per capita of $\$ 34,596$ that is estimated to continue to grow (4). The major sociodemographic challenges of present-day Lithuania include fast-declining population, regional disparities and aging population that may subsequentially incur increasing strains on healthcare system resources (5).

Life-expectancy in Lithuania is 74.7 years (2017 data; 80 years for women and 70 years for men), which is substantially lower than 80.7 years in high-income countries and is the lowest among the EU member countries $(2,6)$. Nineteen percent of population is over 65 years old. Four leading causes of death in Lithuania are ischemic heart disease, stroke, lung cancer and suicide (6). Lithuania also has one the highest amenable mortality rates, indicating an unmet need to optimize effectiveness of healthcare system. Since declaring its independence Lithuania has adopted universal healthcare coverage therefore all citizens of Lithuania are covered by healthcare insurance. The National Health Insurance Fund is a single purchaser of personal health services and is funded by compulsory income-related taxes from all working individuals and by the central government for unemployed citizens and children $(6,7)$. One third of all healthcare expenditures come from private sources (out-of-pocket). In 2016, the total healthcare expenditure in Lithuania constituted $6.7 \%$ of the GDP, which was lower than average healthcare expenditure of the EU-28 countries that was a level of $9.9 \%$ (8). The total healthcare expenditure per inhabitant in Lithuania was 1,543 Eur, which is half of the average expenditure of 2,905 Eur of the EU-28 countries (8). Public and private spending on pharmaceuticals comprise $28 \%$ of the total healthcare expenditure which is one the highest in the EU.

Lithuania has a large network of hospitals that are spread almost across all 60 municipalities. Curative care bed number remains one of the highest in the EU (6). The majority of hospitals in Lithuania and all hospitals that provide neuro-oncology services are non-profit government funded enterprises. To our knowledge, there are no private hospitals performing cranial neurosurgical procedures for brain tumors or delivering adjuvant oncological care (chemotherapy and/or radiation therapy) for glioblastoma (GBM) patients. The number of physicians in Lithuania (4.3 per 1,000 population) is higher than EU average (3.6 per 1,000 population) (6). The density of neurosurgeons is also higher than EU average with 1 neurosurgeon per 50,000 population (9). Healthcare reforms aiming to optimize hospital network, improve hospital treatment effectiveness, improve early detection and treatment of cancers and physician compensation are being implemented or are under-way.

\section{Epidemiology of brain tumors in Lithuania}

According to the National Cancer registry of Lithuania, in 2012 a total of 17,734 of Lithuanian citizens were diagnosed 
with cancer. Of them, 275 patients were diagnosed with malignant brain tumors (ICD codes C70-C72) with approximately 6.7 new cases per 100,000 population (10). GBM is the most common type of glioma comprising $68 \%$ of all gliomas with annual incidence rate of 3.62 per 100,000 population in 2018 (Figure 1) (11). As expected,
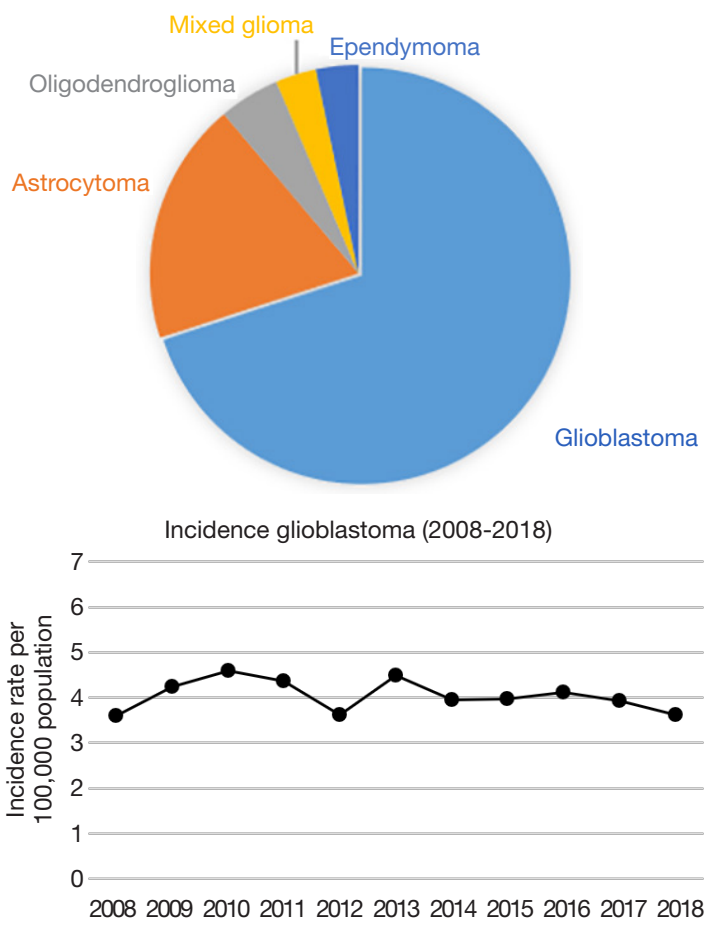

Figure 1 Epidemiology of gliomas and glioblastomas in Lithuania. Source: National Cancer Institute's Cancer registry. the incidence of gliomas increases with advancing age. Specifically, the incidence rate of gliomas was 2.35 per 100,000 population in individuals aged $0-18$ years, 2.76 per 100,000 population in individuals aged $16-34$ years, 5.23 per 100,000 population in individuals aged $35-49$ years, 11.23 per 100,000 population in individuals aged $50-64$ years, 16.1 per 100,000 population in individuals aged 65-74 years, and 11.38 per 100,000 population in individuals older than 75 years. The incidence rate of GBMs is equally distributed between genders.

Incidence of gliomas and GBMs in Lithuania is similar to other industrialized countries. For example, according to the CBTRUS statistical report of brain tumors diagnosed in the United States in 2011-2015, the overall incidence rate of GBMs was 3.21 per 100,000 population (12). According to the RARECANCER registry, the annual incidence of astrocytic tumors in the EU-27 countries was 4.8 per 100,000 population with $63 \%$ being high-grade gliomas (13). The incidence rate of astrocytomas varied from 3 per 100,000 population in Eastern Europe to 5 per 100,000 in the United Kingdom and Ireland.

\section{Current clinical management}

Lithuania has a well-developed network of public hospitals that limits regional disparities of healthcare access. Eight hospitals (five academic centers affiliated with universities and three county hospitals) manage patients with GBM (Table 1). Seven hospitals have neurosurgical services. One center (National Cancer Institute), does not provide neurosurgical services but is capable of performing radiation

Table 1 Academic centers and hospitals that manage glioblastoma patients in Lithuania

\begin{tabular}{|c|c|c|c|c|c|}
\hline Center & City & Academic center & Neurosurgeons & Clinical oncology services & Radiation oncology services \\
\hline $\begin{array}{l}\text { Lithuania University of Health } \\
\text { Sciences Hospital (LSMU) }\end{array}$ & Kaunas & + & + & + & + \\
\hline $\begin{array}{l}\text { Republican Vilnius university } \\
\text { hospital (RVUL) }\end{array}$ & Vilnius & + & + & - & - \\
\hline National cancer institute ( $\mathrm{NCl})$ & Vilnius & + & - & + & + \\
\hline Klaipeda university Hospital & Klaipeda & + & + & + & + \\
\hline Klaipeda county Hospital & Klaipeda & - & + & + & + \\
\hline Siauliai Hospital & Siauliai & - & + & + & + \\
\hline
\end{tabular}


therapy and chemotherapy for GBM patients. An extensive hospital network with a high number of healthcare providers ensures good access to neurosurgery and neuro-oncology services for GBM patients in Lithuania. However, a large network of hospital and providers also poses challenges due to fragmentation of healthcare services that consequentially limits center case load and experience. Diversification of neurosurgery and radiation oncology services also stretches limited healthcare budgets. Furthermore, given the small number of GBM cases in Lithuania, such fragmentation of healthcare services may limit participation in international clinical trials and consequentially patient access to novel therapies.

Healthcare provider licensing in Lithuania is implemented and monitored by the State Health Care Accreditation Agency under the Ministry of Health of the Republic of Lithuania. According to their data (as of 9/30/2019), currently there are 86 neurosurgeons, 88 medical oncologists, 60 radiation oncologists, 78 clinical pathologists, 455 neurologists and 456 radiologists with active medical licenses for practicing in Lithuania (14). In Lithuania there is no formal fellowship training for physicians (neurosurgeons, oncologists, radiologists, pathologists) willing to specialize in neuro-oncology. This can be partly explained by a small number of brain tumor patients in Lithuania and fragmentation of care, hence healthcare providers usually practice across sub-specialties to support their practices. Some physicians pursue additional fellowship training in other EU countries or USA, but these endeavors are usually not funded by the state and this is not a common practice. Neurosurgeons, radiologists and oncologists practicing in major academic centers subspecialize in neuro-oncology but these skills and knowledge are usually acquired during clinical practice after completion of residency training.

All patients with suspected GBM undergo brain MRI. Advanced brain tumor imaging, such as perfusion, susceptibility weighted imaging, functional MRI and nuclear imaging, are available at academic centers. In 2017, there were 37 MRI scanners in Lithuania (20 in public hospitals and 17 in private hospitals). There were 13.1 MRI scanners per 1 million inhabitants, which was lower than the EU average of 14.8 (Eurostat data) to 15.5 (OECD data) scanners per million inhabitants. MRI scanners are available in 8 counties. The majority of MRI scanners in Lithuania (73\%) are medium to low field (1.0 to 1.5 Tesla). The utilization of available MRI scanners in Lithuania (3,820 tests per year) was lower than the EU average. MRI scanners installed in public hospitals were used less frequently than private hospital owned MRI scanners. In 2017 there were 141,346 MRI studies and the average number of MRI studies per MRI scanner (3,820 studies per year) was lower than EU average. Likewise, the number of MRI studies per 100,000 inhabitants in Lithuania was lower than EU average. There were 70 CT scanners in Lithuania in 2017 (57 in public hospitals and 13 in private hospitals). The average use of a CT scanner was similar to EU average (15).

Seven neurosurgical centers perform surgeries for brain tumors in Lithuania. The highest case-load of GBM resection surgeries is in academic centers, which are located in the 3 largest cities of Lithuania: Vilnius, Kaunas, and Klaipeda. Smaller community neurosurgical centers usually perform less than 10 GBM surgeries each year. Academic neurosurgery centers are equipped with stateof-the-art operating rooms with advanced microscopes, navigation systems and intraoperative ultrasound. Awake surgery and intraoperative monitoring are also performed as needed. Intraoperative MRI is available in one academic center. Length of hospital stay after GBM resection surgery typically lasts from 7 to 10 days in uncomplicated cases. Repeated resection of recurrent GBM and other neurosurgical treatments, such as ventriculoperitoneal shunt surgery, are considered on individual basis. Biobanking of surgical specimens is available and routinely performed at academic centers. Centralized biobanks are being developed.

Final diagnosis of glioblastoma is confirmed by clinical pathologists in all cases. Surgical specimens are usually examined by pathologists who specialize in neuro-pathology. In more complicated cases, consultation with partners from other EU hospital is sometimes sought. Diagnosis of GBM is established according to the World Health Organization classification and are revised as needed (16). Assessment for $\mathrm{O}[6]$-methylguanine-DNA methyltransferase (MGMT) methylation status (methylation specific polymerase chain reaction) and isocitrate dehydrogenase (IDH) mutation status (sequencing for IDH1 and IDH2 exon 4 mutations and IDH1 immunohistochemistry labeling) is available since 2015 in major academic centers.

Clinical management of GBM patients in Lithuania is based on the Stupp protocol as a standard of care (17-19). There are no national treatment guidelines of GBM. Radiation therapy is usually started within one month after surgery. Both contrast enhanced MRI and CT are used for radiation therapy planning. Fractionated radiation therapy is the most commonly performed using linear accelerator based fractionated external beam radiation 
therapy. More recently, advanced radiation therapy instruments were acquired by major academic centers, including Leksell Gamma Knife stereotactic radiosurgery system and TrueBeam radiation therapy system.

Temozoloide is approved in Lithuania for treatment of GBM patients and is covered by the National Health Insurance Fund. Temozolomide is the firstline chemotherapeutic treatment option. However, it is sometimes not administered for elderly patients or those in poor functional status $(20,21)$. Anti-angiogenic treatment (bevacizumab) and immunotherapy are not covered for treatment of GBM in Lithuania. Management of recurrent GBMs is challenging and treatment strategies depend on tumor burden, patient's age and functional status. Repeated surgery is considered for resectable tumors. Other treatment options that are considered for recurrent GBMs include radiation therapy (standard or hypo-fractionated) and/or chemotherapy with temozolomide. Alternative chemotherapeutic agents (bevacizumab, lomustine, carmustine, procarbazine) or regiments [PCV regimen: procarbazine, lomustine (CCNU) and vincristine] are considered on a case by case basis.

The major differences between GBM management in Lithuania and USA are accounted by differences in healthcare systems and to some extent by cultural differences. For example, universal healthcare in Lithuania allows all GBM patients (the majority of Lithuanian population) to receive the most effective available therapies as judged needed by the treating team and without a need for prior authorizations by insurance companies. On the other hand, the small number of GBM patients, care fragmentation and lesser funding for healthcare and research, limit availability of clinical trials and secondline treatment options, including immunotherapy. Some therapies that are approved for GBM treatment in the USA, such as tumor treating fields and carmustine wafers, are yet not approved in Lithuania and are therefore not used (22).

Disability is covered for all Lithuanian citizens who are deemed unfit to work. Palliative care services can also be covered but their availability and utilization remain limited.

\section{Potential local barriers to the management of GBM}

While standard of care of GBM patients is readily available and is completely covered for insured Lithuanian citizens, access to clinical trials is limited. According to a search of the clinicaltrials.gov and clinicaltrialsregister. eu databases (September 29, 2019) for clinical trials for GBM patients conducted in Lithuania did not return any ongoing clinical trials. We identified only one terminated study of continuous bevacizumab and lomustine. This is in juxtaposition to the larger number of clinical trials at large US academic medical centers. While participation in clinical trials in other European or non-European countries is possible this route is rarely pursued due to the gravity of the disease prognosis and high-costs of treatment. Growing international collaboration of Lithuanian neurosurgeons and oncologists with other oncology centers can possibly increase clinical trial availability for Lithuanian GBM patients. Lithuanian University of Health Sciences Hospital is a member of the Rare Adult Solid Cancer (ERN EURACAN) network, which is part of the European Reference Networks (23). This EU-funded virtual network connects healthcare providers across EU allowing to promote inter-institutional collaboration opportunities in clinical trials of rare cancers and referring patients to member centers for second opinion or treatment.

Other potential challenges of Lithuanian healthcare systems include insufficient funding for healthcare procedures. Physician compensation remains below EU average and this contributes to emigration of young physicians to practice in other EU countries (24). Decreasing population, physician emigration and growing proportion of elderly individuals is expected to place further constraints on healthcare system that is funded by tax-payers.

\section{Future directions in clinical management and research}

Evidence based treatment options are available for Lithuanian GBM patients. However, due to small population, penetration of novel treatment options for rare disorders in Lithuania can be slower. On the other hand, implementation of EU regulations can help to overcome this barrier.

Collaboration with other academic centers and international consortiums performing clinical trials of novel chemotherapeutic agents and immunotherapy approaches for GBM could improve access of Lithuanian patients to experimental therapies after disease progression and failure of first-line treatment.

Consolidation of GBM patient care in major academic centers could improve patient access to the most experienced treatment teams, and advanced diagnostic and treatment approaches. This could possibly translate to 
better availability of most effective but costly diagnostic and treatment methods and result in better outcomes. However, such a major healthcare system changes would require legislative reforms.

More active involvement of GBM patient organizations and other stakeholders in decision making is encouraged to optimize care of GBM patients. In the recent years there has been an increasing number of online informational resources available to GBM patients in Lithuanian that is expected to improve patient health literacy and engage patients in the decision making.

Clinical and basic neuro-oncology research is performed at academic centers in Vilnius and Kaunas, where scientists are focused on molecular aspects gliomas and patient reported outcome research. Research groups collaborate with EU and US academic centers and often secure national external funding. Research findings of these groups are published in reputable international peer-reviewed journals. Focused funding of experienced neuro-oncology research groups in Lithuania could potentially also contribute to improved care of GBM patients.

\section{Conclusions}

Lithuania is a small and well-developed EU country with publicly funded and well-developed healthcare system that provides state-of-the-art diagnostic and treatment options for GBM patients. Advanced surgical, radiation therapy and chemotherapy treatment modalities are available in major academic centers. The main challenges and opportunities for GBM patient care in Lithuania include consolidation of GBM patient care in major academic centers, facilitation of international collaboration to increase availability of clinical trials, as well as healthcare and research funding.

\section{Acknowledgments}

We would like to thank Prof. Saulius Rocka, MD, PhD, Dr. Jurgis Kyguolis, MD for providing information about management of glioblastoma at their institutions.

Funding: None.

\section{Footnote}

Provenance and Peer Review: This article was commissioned by the Guest Editor (Rimas V Lukas) for the series "The Evolving Landscape of the Management of Glioblastoma" published in Chinese Clinical Oncology. The article did not undergo external peer review.

Conflicts of Interest: All authors have completed the ICMJE uniform disclosure form (available at http://dx.doi. org/10.21037/cco.2019.11.04). The authors have no conflicts of interest to declare.

Ethical Statement: The authors are accountable for all aspects of the work in ensuring that questions related to the accuracy or integrity of any part of the work are appropriately investigated and resolved.

\section{References}

1. Encyclopedia Britannica. Lithuania - History. Available online: https://www.britannica.com/place/Lithuania

2. World Bank. The World Development Indicators: Lithuania. Available online: https://data.worldbank.org/ country/lithuania?view=chart

3. United Nations Development Program. Human Development Reports: Lithuania. Available online: http:// hdr.undp.org/en/composite/trends

4. International Monetary Fund. Report for Selected Countries and Subjects: Lithuania. Available online: https://www.imf.org/external/pubs/ft/weo/2018/01/ weodata/weorept.aspx?sy=1995\&ey=2023\&scsm=1\&ss $\mathrm{d}=1 \&$ sort $=$ country $\& \mathrm{ds}=. \& \mathrm{br}=1 \& \mathrm{c}=946 \& \mathrm{~s}=\mathrm{NGDP} \_R P$ CH,PPPGDP,PPPPC,PCPIPCH,LUR,GGXWDG NGDP\&grp $=0 \& a=\& p r . x=38 \& p r . y=5$

5. Ubarevičiené $R$, Ham $M$ van. Population decline in Lithuania: who lives in declining regions and who leaves? Reg Stud Reg Sci 2017;4:57-79.

6. OECD/European Observatory on Health Systems and Policies. Lithuania: Country Health Profile 2017. Available online: https://www.oecd-ilibrary.org/socialissues-migration-health/lithuania-country-health-profile2017_9789264283473-en

7. Murauskiene L, Janoniene R, Veniute M, et al. Lithuania: health system review. Health Syst Transit 2013;15:1-150.

8. Healthcare expenditure statistics - Statistics Explained. Available online: https://ec.europa.eu/eurostat/statisticsexplained/index.php/Healthcare_expenditure_statistics

9. Reulen HJ, Hide RA, Bettag M, et al. A report on neurosurgical workforce in the countries of the $\mathrm{EU}$ and associated states. Task Force "Workforce Planning", UEMS Section of Neurosurgery. Acta Neurochir (Wien) 2009;151:715-21.

10. Giedrè Smailytė; Birutè Aleknavičienè. Vèžys Lietuvoje 
2012 metas. Vilnius, Lithuania: Nacionalinis vèžio institutas; 2015. Available online: https://www.nvi.lt/ uploads/pdf/Vezio\%20registras/Vezys_lietuvoje_2012.pdf

11. Rasa Sadeckaite. Sergamumas pirminiais piktybiniais centrinès nervų sistemos navikais Lietuvoje 2007-2014 metais. [Kaunas, Lithuania]: Lithuanian University of Health Science; 2016.

12. CBTRUS Statistical Report: Primary Brain and Other Central Nervous System Tumors Diagnosed in the United States in 2011-2015 | Neuro-Oncology | Oxford Academic. Available online: https://academic.oup.com/ neuro-oncology/article/20/suppl_4/iv1/5090960

13. Crocetti E, Trama A, Stiller C, et al. Epidemiology of glial and non-glial brain tumours in Europe. Eur J Cancer 2012;48:1532-42.

14. Valstybinè akreditavimo sveikatos priežiūros veiklai tarnyba prie Sveikatos apsaugos ministerijos. Available online: https://licencijavimas.vaspvt.gov.lt/License/ PublicSpecialistIndex

15. Brangios medicinos priemonès (prietaisai) Lietuvoje ir užsienyje I VASPVT. Available online: https://www.vaspvt. gov.lt/node/360

16. Louis DN, Cancer IA for R on, Wiestler OD, Ohgaki H. WHO Classification of Tumours of the Central Nervous System. International Agency for Research on Cancer; 2016. Available online: https://books.google.co.uk/ books?id=JWXWjwEACAAJ

Cite this article as: Bunevicius A, Usinskiene J, Buneviciene I, Vincerzevskiene I. Management of glioblastoma: a perspective from Lithuania. Chin Clin Oncol 2021;10(4):41. doi: 10.21037/ cco.2019.11.04
17. Weller M, van den Bent M, Tonn JC, et al. European Association for Neuro-Oncology (EANO) guideline on the diagnosis and treatment of adult astrocytic and oligodendroglial gliomas. Lancet Oncol 2017;18:e315-29.

18. NCCN Clinical practice Guideliness in Oncology. Central Nevous System Cancers. Version 2.2019 - September 16, 2019.. Available online: https://www.nccn.org/ professionals/physician_gls/pdf/cns.pdf

19. Stupp R, Mason WP, van den Bent MJ, et al. Radiotherapy plus concomitant and adjuvant temozolomide for glioblastoma. N Engl J Med 2005;352:987-96.

20. Young JS, Chmura SJ, Wainwright DA, et al. Management of glioblastoma in elderly patients. J Neurol Sci 2017;380:250-5.

21. Minniti G, Lombardi G, Paolini S. Glioblastoma in Elderly Patients: Current Management and Future Perspectives. Cancers (Basel) 2019;11(3). doi: 10.3390/ cancers11030336.

22. Drugs Approved for Brain Tumors. National Cancer Institute. 2012 [cited 2019 Sep 30]. Available online: https:// www.cancer.gov/about-cancer/treatment/drugs/brain

23. ERN EURACAN. ERN EURACAN. Available online: http://euracan.ern-net.eu/

24. Goštautaitė B, Bučiūnienė I, Milašauskienè Ž, et al. Migration intentions of Lithuanian physicians, nurses, residents and medical students. Health Policy 2018;122:1126-31. 